\title{
Evaluation of the SALTMED model for tomato crop production in unheated greenhouses
}

\author{
L.L. Silva1,a, F.J. Baptista1, J.F. Meneses ${ }^{2}$ and R. Ragab ${ }^{3}$
}

1Departamento de Engenharia Rural, ECT, and Instituto de Ciências Agrárias e Ambientais Mediterrânicas (ICAAM), Universidade de Évora, Évora, Portugal; ${ }^{2}$ Instituto Superior de Agronomia, Universidade de Lisboa, Lisboa, Portugal, ${ }^{3}$ Centre for Ecology and Hydrology (CEH), Wallingford, UK.

\begin{abstract}
The SALTMED model is one of the few available generic models that can be used to simulate crop growth with an integrated approach considering water, crop, soil and field management. It is a physically based model using the well-known water and solute transport, evapotranspiration, and water uptake equations. The possibility of using models able to simulate crop growth with this integrated approach can be very useful for farmers as a decision support tool, helping with decisions such as: what crop/variety to use, when to plant and harvest, when and how much to irrigate, what yield to expect under a specific irrigation system or strategy, when using a certain water quality, and also to allow increasing water use efficiency and crops productivity. The SALTMED model has been calibrated and validated for several field crops, in several parts of the world, including field tomato. However, the greenhouse environment has specific conditions that are not always easy to simulate with generic crop growth models. The objective of this work was to evaluate SALTMED model for a tomato crop grown in unheated greenhouse conditions. Climatic data and crop parameters were recorded during two years, in two greenhouses with different ventilation management, and three different sets of data were used to calibrate and to validate the model. The results showed that the model can accurately simulate soil grown tomato crop yield under Mediterranean unheated greenhouse conditions.
\end{abstract}

Keywords: crop growth modeling, plastic greenhouses, soil grown crops, Mediterranean conditions

\section{INTRODUCTION}

Irrigation and climate control management in greenhouses are very important factors to improve water use and achieve sustainable crop production systems. Field experiments to determine the impact of different irrigation and climate control strategies on crop yield are important, and necessary, but require time and money. Computer programs able to simulate crop growth using different field management strategies can be very useful tools to increase water use efficiency and productivity. Sivakumar and Glinni (2002) presented, and briefly described, several crop growth models, but most of them were single crop models or crop growth models for specific applications. These models can be very useful for a certain research objectives, but cannot be used for more general conditions or for on-farm decisions. The extension services and farmers need models that can help them to make decisions such as what crop/variety to use, when to plant and harvest, when and how much to irrigate, the effects of different fertilizer strategies, the effects of using water with different salinity levels, etc, and that can give them a value of possible yield to be obtained in each case.

The SALTMED model (Ragab, 2002; Ragab et al., 2005a, b) is one of the few available models that has been developed for such generic applications and has proved its ability to simulate several crops and agricultural situations. It is a physically based model using the well-known water and solute transport, evapotranspiration, and water uptake equations, and is a user-friendly model, benefiting from the Windows ${ }^{\mathrm{TM}}$ environment. It simulates evapotranspiration, plant water uptake, water and solute transport under different

${ }^{a}$ E-mail: Ilsilva@uevora.pt 